\title{
Autonomic regulation of splanchnic circulation
}

\author{
KATHLEEN A FRASER, SAMUEL S LEE
}

\begin{abstract}
KA FRASER, SS LEE. Autonomic regulation of splanchnic circulation. Can J Gastroenterol 1991;5(4):147-153. The role of the autonomic nervous system in circulatory regulation of the splanchnic organs (stomach, small intestine, colon, liver, pancreas and spleen) is reviewed. In general, the sympathetic nervous system is primarily involved in vasoconstriction, while the parasympathetic contributes to vasodilation. Vasoconstriction in the splanchnic circulation appears to be mediated by alpha- 2 receptors and vasodilation by activation of primary afferent nerves with subsequent release of vasodilatory peptides, or by stimulation of beta-adrenergic receptors. As well, an important function of the autonomic nervous system is to provide a mechanism by which splanchnic vascular reserve can be mobilized during stress to maintain overall cardiovascular homeostasis.
\end{abstract}

Key Words: Autonomic nervous system, Parasympathetic nerves, Splanchnic circulation, Sympathetic nerves

\section{Régulation autonomique de la circulation splanchnique}

RESUME: Les auteurs examinent le rôle du système nerveux autonome dans la régulation du système circulatoire des organes splanchniques (estomac, intestin grêle, côlon, foie, pancréas et rate). En général, le système nerveux sympathique intervient principalement dans la vasoconstriction tandis que le parasympathique contribue à la vasodilatation. La vasoconstriction semble déclenchée par les récepteurs alpha 2 et la vasodilatation par l'activation des nerfs afférents primaires provoquant la libération de peptides vasodilatateurs ou par la stimulation des récepteurs bêta adrénergiques. Une des fonctions importantes du système nerveux autonome est également de fournir un mécanisme permettant de mobiliser la réserve vasculaire splanchnique durant le stress afin de maintenir l'homéostase cardiovasculaire globale.

Gastroenterology Research Group, University of Calgary, Calgary, Alberta

Correspondence and "eprints: Dr SS Lee, 3330 Hospital Drive NW, Calgary. Alberta T2N 4N1. Telephone (403) 220-4500

Received for publication May 13, 1991. Accepted July 8, 1991
$\mathrm{T}$

HE SPLANCHNIC ORGANS ARE capable of controlling their moment-to-moment bloodflow and oxygenation to a certain extent, even when neural and/or humoral input is eliminated (1). The ability to self-regulate bloodflow in the splanchnic organs has been attributed to myogenic, metabolic and neurocrine influences on resistance and exchange vessels (1). Despite the autonomy of bloodflow regulation in the splanchnic organs, the autonomic nervous system is thought to provide a more sophisticated level of control. In addition, autonomic nerves provide a mechanism to maintain overall cardiovascular homeostasis by overriding local influences, such that splanchnic blood can be quickly redirected to vital organs during emergency states in the organism (2).

The autonomic nervous system is comprised of sympathetic (thoracolumbar) and parasympathetic (craniosacral) nerves. Sympathetic nerves are primarily involved in vasoconstriction and parasympathetic in vasodilation. Preganglionic cell bodies of the sympathetic nerves are located in the intermediolateral cell column in the grey substance of the spinal cord. Axons from these cell bodies exit the spinal 
cord via the ventral roots, passing through the white communicating ramus (myelinated) to enter the first of two sympathetic ganglia, the paravertebral or sympathetic ganglia. The axon will do one of two things: it will synapse in the chain, either cranially or caudally to the point at which it entered; or it will pass directly through the sympathetic chain without synapsing, to become part of the splanchnic nerves targeted to enter one of three prevertebral ganglia: celiac, superior mesenteric or inferior mesenteric ganglia. After synapsing in the prevertebral ganglia, post ganglionic fibres travel to the organ to be innervated. In the first option, after synapsing in the chain the post ganglionic fibres exit the chain to re-enter the spinal nerve trunk via the grey communicating ramus (unmyelinated) and project to visceral structures in the periphery (3).

Alternatively, cell bodies of preganglionic fibres in the parasympathetic nervous system originate in either nerve nuclei of the brainstem (iii, vii, ix or $\mathrm{x}$ ), or sacral levels of the spinal cord (S1 to S3). Preganglionic fibres characteristically terminate in parasympathetic ganglia in or near the organ innervated, typically in the walls of the organ innervated. As such, the post ganglionic fibres are relatively short and located in the wall of the organ to be innervated as well. Parasympathetic innervation to the abdominal viscera is provided by the vagus, whereas the pelvic nerve innervates the pelvic viscera. Typically, both pre- and post ganglionic parasympathetic fibres and preganglionic sympathetic fibres release cholinergic agents, while post ganglionic sympathetic fibres release adrenergic transmitters (3).

Finally, certain specific visceral afferent fibres provide sensory feedback to higher centres. These primary afferents project to the brain and spinal cord via the autonomic nerves (3).

\section{BLOODFLOW REGULATION IN SPLANCHNIC CIRCULATION}

Bloodflow to the colon and stomach is significantly less than to the intestine, while in the colon and intestine, proximal segments receive a greater proportion of bloodflow than distal (1). Generally speaking, the submucosalmucosal regions receive a greater share of bloodflow than do the muscularis layers (1). The microcirculatory architecture of the stomach and colon is relatively similar, while the circulation in the small intestine is quite unique by comparison. Like the liver, the pancreas is perfused with both venous and arterial blood (1). Typically, within the microcirculation of the splanchnic organs, bloodflow is modified by precapillary resistance vessels (4).

In the following sections the microvascular circulation of the splanchnic organs (stomach, small intestine, colon, liver, pancreas and spleen) and their modification by the autonomic nervous system are described.

\section{THE GASTRIC CIRCULATION}

Large arteries pierce the muscle layers of the stomach to become progressively smaller as they supply the muscularis and submucosal regions. Arterial plexuses located in the submucosa send mucosal arterioles to supply capillaries at the base of the mucosa, after passing perpendicularly through the muscularis mucosa. Collecting venules located in the mucosa carry blood from the mucosa to the submucosa, where it enters the venular plexus. Blood exiting the venular plexuses enters larger veins that drain the stomach. Within the muscle layers (superficial and deep) there is free communication between capillaries on the same or different planes. The muscle capillary networks drain into venules to join veins from the venular plexus. These veins combine with larger veins ultimately to drain the stomach (5). Because the muscle vascular bed is parallel to the submucosal-mucosal beds, mucosal bloodflow can be controlled by constriction or dilation of the submucosal arteriole plexus (6).

\section{CONTROL OF GASTRIC BLOODFLOW}

Sympathetic regulation: Sympathetic input to the stomach arises from T6 to L10 of the spinal cord and terminates as preganglionic fibres in the celiac gang- lion. Post ganglionic fibres exit the celiac ganglion to innervate the stomach (5). Arteries and arterioles are more heavily adrenergically supplied than veins or venules, while in capillaries adrenergic innervation is relatively uncommon (7). However, more recent work has demonstrated some adrenergic innervation of the capillary endothelium at the basal and middle portions of the mucosa.

Vasoconstriction produced by electrical stimulation of sympathetic efferents decreases bloodflow to the stomach and mucosa (8), including celiac (9) and gastroepiploic arterial flow (10). However, with prolonged stimulation of gastric sympathetic fibres, escape from vasoconstriction results, and bloodflow reaches a higher but stable level. This phenomenon, termed 'autoregulatory escape' (11), occurs in most splanchnic organs. Initial vasoconstriction appears to be mediated by alpha-adrenergic receptors, and escape from vasoconstriction (vasodilation) by beta-adrenergic (5) or primary afferent innervation.

Catecholamine effects on gastric circulation are divergent. Adrenaline typically elicits vasodilation, whereas noradrenaline administration results in vasoconstriction when infused intravenously (12). Intra-arterial infusion of adrenaline and noradrenaline into the left and right gastric arteries produces immediate vasoconstriction succeeded by autoregulatory escape and subsequent vasodilation. The constrictor response is abolished by alpha-adrenergic blockade, and the dilatory effect is blocked by beta-adrenergic blockade (13). More specifically, others have shown marked vasoconstriction at the level of the gastric submucosal arteriolar vascular bed immediately following adrenaline or noradrenaline administration (14). The literature therefore supports the conclusion that both catecholamines initially constrict gastric vessels.

Parasympathetic regulation: The area postrema appears to be the origin of the nerve fibres innervating the fundus and corpus of the stomach in the rat (15). Parasympathetic fibres that innervate the stomach arise from the vagus, which 
consists of both high and low threshold fibres. Stimulation of the low threshold vagal fibres results in a nonadrenergicnoncholinergic relaxation of the stomach and a concomitant increase in bloodflow (16). Following vagal stimulation, the gastric arteriolar diameter increases (7), producing a sharp increase in bloodflow. Given the resistance of arteriolar diameter to cholinergic antagonists (atropine-muscarinic blocker), a noncholinergic dilatory effect is suggested $(7,17)$.

Studies of canine gastric arteries have shown that vagal stimulation can depress the vasoconstrictive response to adrenergic stimulation (18), thus suggesting cholinergic inhibition of adrenergic neurotransmission. The study provided evidence of muscarinic receptors on sympathetic nerve endings inhibiting or dulling adrenergic neurotransmission.

\section{INTESTINAL CIRCULATION}

Microcirculation: The microcirculation of the intestine is different from the vascular arrangement in the stomach. The submucosa, mucosa and muscularis layers of the small intestine all maintain fairly distinct vascular beds. The arterial plexus, located in the submucosa, supplies all three layers directly, as well as sending a single arteriole to the villus tip. A consecutive arrangement between the arterioles, precapillary sphincters, capillaries and venules exists in each layer of the intestine. The first order arterioles supplying the wall of the intestine originate from mesenteric arteries. These arterioles then pierce the muscle walls (longitudinal and circular) and continue through the submucosa, where second and third order arterioles arise and supply the submucosa and mucosa to the tip of the villus. A branch of the second and third order arterioles, the fourth order, passes back to supply the muscle layers. Small venules drain each layer independently and eventually all bloodflow drains into larger veins, ultimately to draining the intestine (19).

The arterial and venous portions supplying the villus are believed to autoregulate more successfully than the deeper vessels. The villus is supplied by a main arteriole, the smaller supplying branched arterioles of which extend to the capillary bed at the tip of the villus. The capillaries drain into several small venules, to drain eventually into a larger venule located at the base of the villus. A discriminating feature of villus circulation in cats (20), dogs (21) and humans (22) is the presence of a countercurrent exchange mechanism. The venule and arterioles supplying the villus lie in close proximity to each other (10 to $20 \mu \mathrm{m})(23)$, and as a result blood in the venule and capillaries flows in a direction opposite to arterial flow. It interesting to note that a countercurrent mechanism has not been established in rat or rabbit intestine (24).

Sympathetic regulation: Low frequency $(4$ to $8 \mathrm{~Hz}$ ) sympathetic stimulation of nerves in the intestinal vascular bed results in marked vasoconstriction followed by a decrease in bloodflow to the whole intestine mucosa, submucosa and muscle layers. As well, catecholamine release from either sympathetic post synaptic receptors or the adrenal cortex produces intense vasoconstriction with subsequent dilation and increased flow - an autoregulatory response (25). The mechanism responsible for autoregulatory escape in the intestine had been unclear until a recent study demonstrated that post ganglionic sympathetic nervous stimulation activates both vasoconstrictor sympathetic fibres and vasodilator afferent capsaicin-sensitive C-fibres (26). It is generally accepted that the initial vasoconstriction is mediated by alpha- 2 adrenergic receptors (27), whereas stimulation of afferent nerves releases vasodilator peptides such as substance $\mathrm{P}$ or calcitonin gene-related peptide.

Adrenergic agents have been heavily investigated as to their effects on intestinal bloodflow. LeNoble et al (28) compared the effects of sympathetic stimulation with exogenously applied adrenergic agents on both macrovascular and microvascular dynamics. Intra-arterial (superior mesenteric artery) application of both phenylephrine (an alpha-adrenergic agonist) and noradrenaline produced sharp decreases in superior mesenteric bloodflow, followed by a decrease in diameter at the level of the A2 arterioles in the small intestine, as measured by intravital microscopy.

In summary, the bulk of evidence demonstrates functionally different roles for alpha- and beta-adrenergic receptors in the intestine. Alpha-2 receptor activation with phenylephrine results in vasoconstriction, while vasodilation is produced by either betaadrenergic activation (29) or stimulation of primary afferent fibres and the subsequent release of vasodilator peptides (28). As well, agents such as digitalis (30) and nicotine (31) appear to act through noradrenaline.

Parasympathetic regulation: Evidence for parasympathetic regulation of intestinal bloodflow is at best unclear. At present, evidence for parasympathetic regulation of the mesentery is lacking (5); accordingly, direct vagal stimulation has no vasoactive effect (32).

However, studies examining the mechanisms of postprandial hyperemia have demonstrated both sympathetic and parasympathetic involvement. The splanchnic vascular response to feeding can be divided into two phases: that developing during the anticipatory phase prior to food ingestion; and that produced following digestion and $a b$ sorption.

During the first phase, the resistance of the mesenteric vascular bed increases (33), while overall cardiac output increases. This is thought to be due to a higher cortical anticipatory response mediated by increased sympathetic activity. After feeding, in the second phase, mesenteric vascular resistance decreases and cardiovascular variables return to normal $(34,35)$. Decreased resistance is marked by an increase in bloodflow from 28 to $132 \%$ in the superior mesenteric artery (33). This vasodilation can be inhibited by atropine, implying cholinergic innervation of the superior mesenteric artery (33). Microsphere experiments have localized the hyperemic response to the mucosa-submucosa and muscularis regions of the intestinal wall. 


\section{COLON AND RECTUM}

The microvascular design of the colon is very similar to that of the stomach. Blood vessels supplying the submucosa and mucosa parallel those supplying the muscle layers. Evidently, the mucosa-submucosa receives the greatest bloodflow (36).

Sympathetic regulation: Sympathetic nervous innervation of the colon is provided by both splanchnic and lumbar nerves. The proximal colon is innervated by splanchnic vasoconstrictor fibres, whereas the distal colon is innervated by the lumbar nerves (37). Sympathetic stimulation produces immediate but brief vasoconstriction followed by autoregulatory escape. There appears to be no escape at the level of the precapillary sphincters. Responses mediated by resistance or exchange vessels in the colon are less dramatic than those in the small intestine (37). There is scant information about sympathetic influence on circulation in the rectum (36).

Parasympathetic regulation: Parasympathetic innervation to the colon and rectum arises from the pelvic nerves. Stimulation के the pelvic nerve initiates very different responses in the colon and rectum (38). Pelvic nerve stimulation produces a brief hyperemia followed by an increase in bloodflow to the colon (37). The same stimulation causes immediate and sustained vasodilation in the rectum (38). Ganglionic blockade destroys pelvic nerve vasodilation of the colon and rectum, suggesting involvement of a noncholinergic transmitter.

Vasoactive intestinal polypeptide (VIP) has been suggested as the noncholinergic transmitter involved (39). Pelvic nerve stimulation releases VIP from both rectum (38) and colon (40). Sympathetic release of VIP correlates with vasodilatory responses in the vessels of the colon. Analogously, exogenous VIP (intra-arterial infusion) application produces vasodilation in both colon and rectum (38). Furthermore, other substances have been suggested as possible mediators of the vasodilation evidenced after pelvic nerve stimulation (substance $\mathrm{P}$, serotonin, purinergic nerve, kinin system) (41).

\section{HEPATIC CIRCULATION}

Intrahepatic branches of the portal vein become progressively smaller as they course through the liver. Conducting veins $(400 \mu \mathrm{m})$ branch into distributing veins (less than $28 \mu \mathrm{m}$, either marginal or maximal) which further subdivide into smaller terminal venules to unite eventually with sinusoidal beds via small inlet venules (42).

The hepatic artery runs alongside the portal vein into the portal canals of the liver. Once inside the liver, the hepatic artery branches into arterioles. Terminal arterioles ( 10 to $50 \mu \mathrm{m}$ ) end as precapillaries (sphincters) to penetrate the capillaries of the liver. Capillaries then drain into specialized capillaries lined with Kupffer and endothelial cells, termed 'liver sinusoids'.

Sphincters have been identified in numerous locations throughout the liver. Consequently, bloodflow regulation inside the liver can be modified at the bifurcation of the arterioles in the portal canals, in precapillaries, at the point where arterioles join the sinusoids, in the inlet venules, and in the branches of the portal vein (43).

Because portal flow is the sum of bloodflow from the extrasplanchnic circulation, resistance is largely determined by arteriolar adjustment in the splanchnic organs. Portal resistance within the liver had been thought to be largely presinusoidal (2), but Lautt and colleagues $(44,45)$ have recently demonstrated the existence of sphincterlike structures in the small hepatic veins of cats and dogs, suggesting a predominantly post sinusoidal site of resistance.

Innervation: The liver maintains the ability to control total hepatic bloodflow by the hepatic arterial buffer response (as portal venous flow rises or decreases, hepatic arterial flow compensates by decreasing or increasing). Although intrinsic mechanisms exist to regulate bloodflow in the liver, the hepatic circulation is also influenced by a host of extrinsic nerves that have significant hemodynamic consequences. Extrinsic nervous supply to the liver arises by two plexuses, the anterior plexus and the posterior plexus. The anterior plexus, composed of branches originating in the left and right celiac ganglion and the left vagus nerve, is located along the common hepatic artery. The posterior plexus, derived from the right celiac ganglion and right vagus, wraps around the bile duct and portal vein. Both plexuses can communicate with one another. Sympathetic and parasympathetic fibres are carried by the anterior plexus (46). Anterior plexus denervation sig. nificantly alters sympathetically mediated vasoconstriction (47).

Sympathetic regulation: The liver receives neural innervation from sympathetic fibres (T7 to T10) via the celiac plexus (46). Rat liver hepatocytes appear to have very little adrenergic innervation. However, nerve fibres surrounding the preterminal hepatic artery and portal vein are innervated by both adrenergic and cholinergic fibres. Generally speaking, there seems to be a minimal role for hepatic nerves in the control of hepatic arterial bloodflow, given that hepatic denervation produces no effect on hepatic bloodflow (48).

The hepatic artery is abundantly supplied by adrenergic nerves. Stimulation of nerves surrounding the celiac artery in rats produces intense vasoconstriction of portal venules, hepatic arterioles and sinusoids (49). The vasoconstriction is presumably mediated by alpha-adrenergic receptors $(50)$, as it can be blocked by phentolamine (alpha-adrenergic antagonist) (51). Following cessation of stimulation, a period of hyperemia is produced in the hepatic artery. The mechanism of vascular escape is poorly understood, but is thought to involve beta-adrenoceptor activation (51).

Hepatic venous sphincters appear to be under sympathetic control, since noradrenaline and angiotensin administration produce marked constriction (50).

There appears to be no neural control of the portal vein itself, so pressure changes are mainly due to changes in resistance vessels in the splanchnic viscera (4). Branches of the portal vein inside the liver may be influenced by alpha-adrenergic mechanisms (46). 
Parasympathetic regulation: Vagal stimulation is thought to result in dilation of sinusoids with a decrease in the velocity of bloodflow and increases in the number of sinusoids being perfused at any one time $(52,53)$. However, this is still controversial as others have found no effect of vagal stimulation on hepatic bloodflow regulation (54). Reilly et al (55) found that cholinergic agents produced vasoconstriction in both sinusoids and portal and terminal hepatic venules, a response that could be blocked by alpha-adrenergic blockers but not atropine.

\section{PANCREAS}

Microvascular anatomy: Little information is available on the pancreatic microcirculation (4). The most accepted view of pancreatic circulation holds that the pancreas, like the liver, is characterized by a portal circulation, with exocrine tissue being perfused by both venous and arterial blood (56). The arteries supplying the pancreas advance along the ducts to diverge into intralobular arteries, which then divide into arteriolar branches to supply the capillary network of islets, the capillary plexus of the acini, and the periductular capillary plexus. Efferents of the islet capillary network either pass through the insuloacinar portal vessels to the acinar capillary plexus, or drain through the intralobular veins. Vessels exiting the acinar capillary network either pass through the capillary plexus or empty into the intralobular veins to exit the gland (1).

The current view holds that arterial flow supplies the islets and exocrine tissue separately, while blood flows to the exocrine pancreas via capillaries from the islets (57).

A determination of arterial bloodflow supplying the islets and acini individually was found to be 11 to $23 \%$ and 77 to $89 \%$, respectively (58).

Sympathetic and parasympathetic regulation: Very little work has been done on autonomic control of the pancreatic circulation, because most studies have concentrated primarily on its secretory role (insulin and glucagon). Autonomic regulation of the pan- creas appears to be similar to that of the rest of the gastrointestinal system. Stimulation of sympathetic efferents elicits prompt vasoconstriction, whereas vagal stimulation produces vasodilation.

\section{SPLEEN}

Sympathetic regulation: Sympathetic innervation of the spleen arises from the splenic nerve via the celiac ganglion. According to Baron and Janig (59), of the approximately 13,200 neurons that project to the splenic nerve, 1255 are sympathetic post ganglionic neurons arising from either the prevertebral $(98 \%)$ or paravertebral $(2 \%)$ sympathetic ganglia. As well, 650 afferent neurons project to the splenic nerve. Sympathetic stimulation of the splenic nerve in dogs and cats results in decreased bloodflow (60), presumably a result of activation of the sympathetic noradrenergic neurons that innervate the arterioles, veins and trabeculae of the spleen (61).

Autoregulatory ability of the splenic circulation is thought to be weak, presumably due to its lesser functional importance in times of stress (62). Vasodilation of vessels in the spleen is presumed to result from activation of primary afferents carried in the splenic nerve, triggering bradykinin (vasoilator peptide) receptor release (63).

\section{VISCERAL AFFERENTS AND REFLEX ARCS}

The central nervous system receives considerable innervation from visceral afferents in the splanchnic organs. The majority (54\%) of those afferents travel with the sympathetic nerves. The central nervous system also receives vagal afferents, the majority of which travel through the thoracic vagus. The primary afferents can be activated by any one of the following stimuli: vibration, smooth muscle contraction, noxious stimuli or chemoreceptors (64). Therefore, stimulation of the primary visceral afferents can invoke a reflex response involving spinal or supraspinal neural pathways. As mentioned previously, some primary afferents may be involved in the vasodilatory response of autoregulation. However, other physiological roles in the splanchnic circulation remain yet unclear (1).

\section{THE ROLE OF THE SPLANCHNIC CIRCULATION IN OVERALL CARDIO. VASCULAR HOMEOSTASIS}

The capacitance vessels of the splanchnic bed contain approximately 20 to $30 \%$ of the total blood volume of the body (65). The liver, spleen and intestine together form the splanchnic blood reservoir - a reservoir that can be mobilized by the sympathetic nervous system to maintain cardiovascular homeostasis. Approximately 30 to $40 \%$ of this volume can be expelled by sympathetic stimulation in response to an emergency (2). For instance, when blood is removed or infused at a fairly slow pace, compensatory mechanisms can act either to remove blood from the reservoir and redirect it to the appropriate region or, in the case of excess, direct it to the splanchnic reserve (66).

Mobilization of the splanchnic blood appears to be the result of sympathetic vasoconstriction of arterioles (33). More specifically, the mobilization of splanchnic blood during hemorrhage can best be characterized by three stages. In the initial stage, low and high pressure baroreceptors in the carotid arteries and aortic arch lessen venous return by responding to decreasing pressure. Subsequently, chemoreceptors located in the intrathoracic vessels and heart are activated by decreased arterial $\mathrm{pH}$. The consequence of both of these actions is to initiate vasoconstriction of the resistance vessels - a response accomplished primarily by sympathetic nerves. The vasoconstriction evoked by hemorrhage accounts for roughly one-third of the increased overall peripheral resistance.

To conclude, the autonomic nervous system plays an essential role in the regulation of bloodflow to individual splanchnic organs. In addition, it helps to mobilize the splanchnic vascular reserve to help maintain overall cardiovascular homeostasis in an emergency. 


\section{REFERENCES}

1. Perry RA, Ardell JL, Barrowman JA, Kvietys PR. Physiology of the splanchnic circulation. In: Kvietys PR, Barrowman JA, Granger N, eds. Pathophysiology of the Splanchnic Circulation. Boca Raton: CRC Press, 1987:1-56.

2. Greenway CV. Role of the splanchnic venous system in overall cardiovascular homeostasis. Fed Proc 1983;42:1678-84.

3. Carpenter B, Sutin J. The autonomic nervous system. Human Neuroanatomy, 8 th edn. Baltimore: Waverly Press, 1983:209-31.

4. Henrich HA. Precapillary control of the splanchnic vascular bed.

J Cardiovasc Pharmacol 1985;7:S73-9.

5. Guth PH, Leung FW. Physiology of the gastric circulation. In: Johnson LR, ed. Physiology of the Gastrointestinal Tract, 2 nd edn. New York: Raven Press, 1986:1011-30.

6. Guth PH, Smith E. Neural control of gastric mucosal bloodflow in the rat. Gastroenterology 1975;69:935-40.

7. Furness JB. The adrenergic innervation of the vessels supplying and draining the gastrointestinal tract. Z Zeliforsch 1971;113:67-82.

8. Yano S, Fujiwara A, Ozaki Y, Harada M. Gastric bloodflow responses to autonomic nerve stimulation and related pharmacological studies in rats. J Pharm Pharmacol 1983;35:642-6.

9. Guth PH, Smith E. Nervous regulation of the gastric microcirculation. In: Brooks FP, Evers PW, eds. Nerves and the Gut. New York: Charles B Slack, 1987:365-73.

10. Ohya Y, Guth PH. Effects of topical ethanol on rat gastric mucosa microcirculation. Clin Res 1985;33:37-43.

11. Ross G. Escape of mesenteric vessels from adrenergic and nonadrenergic vasoconstriction. Am J Physiol 1971;221:1217-22.

12. Nicoloff DM, Peter ET, Stone NH, Wagesteen OH. Effects of catecholamines on gastric secretion and bloodflow. Ann Surg 1964;159:32-6.

13. Zinner MJ, Kerr JC, Reynolds DJ. Adrenergic mechanisms in canine gastric circulation. Am J Physiol 1975;229:977-82.

14. Guth PH, Smith E. Vasoactive agents and the gastric microcirculation. Microvasc Res 1974;8:125-31.

15. Ewart WR, Jones MV, King BF. Central origin of vagal nerve fibres innervating the fundus and corpus of the stomach in the rat. J Auton Nerv Syst 1988;25:219-31.

16. Martinson J. The effect of graded vagal stimulation on gastric motility, secretion and bloodflow in the cat. Acta Physiol Scand 1965;65:300-9.

17. Zinner MJ, Jaffe BM, DeMagistris L, Dahistrom A, Ahlman H. Effect of cervical and thoracic vagal stimulation on luminal serotonin release and regional bloodflow in cats. Gastroenterology 1982;82:1403-8.

18. Van Hee RH, Vanhoutte PM. Cholinergic inhibition of adrenergic neurotransmission in the canine gastric artery. Gastroenterology 1978;74:1266-70.

19. Parks DA, Jacobson ED. Mesenteric circulation. In: Johnson LR, ed. Physiology of the Gastrointestinal Tract, 2nd edn. New York: Raven Press, 1987:1649-70.

20. Jodal M, Hallback D, Lundgren O Tissue osmolality in the intestinal villus during luminal perfusion with isotonic electrolyte solutions. Acta Physiol Scand 1978;102:94-107.

21. Bond JH, Levitt DG, Levitt, MD. Quantification of countercurrent exchange during passive absorption form the dog small intestine. J Clin Invest 1977;59:308-18

22. Hallback DA, Hulten L, Jodal M, Lindhagen J, Lundgren O. Evidence for the existence of a countercurrent exchanger in the small intestine in man. Gastroenterology 1978;74:683-90.

23. Lundgren $\mathrm{O}$. The circulation of the small bowel mucosa. Gut 1974;15:1005-13.

24. Mickflikier AB, Bond JH, Sircar B, Levitt MD. Intestinal villus bloodflow measured with carbon monoxide and microspheres. Am J Physiol 1976;230:916-9.

25. Shepard AP, Pawlik W, Mailman D, Burks TF, Jacobson ED. Effects of vasoconstrictor in intestinal vascular resistance and oxygen consumption. Am J Physiol 1976;230:298-305.

26. Remak G, Hottenstein OD, Jaconson E. Sensory nerves mediated neurogenic escape in rat gut. Am Physiol Soc 1990;258:H778-86.

27. Greenway CV, Lister GE. Capacitance effects and blood reservoir function in the splanchnic vascular bed during non-hypertensive haemorrhage and blood volume expansion in anaesthetized cats and dogs. J Physiol 1977;237:279-4

28. Le Noble LM, Tangelder GJ, Slaaf DW, Smits JFM, Struyker-Boudier HAJ. Adrenergic stimulation of the rat mesenteric vascular bed: A combined micro- and macrocirculatory study. Pflugers Arch 1987;410:250-6.

29. Swan KG, Reynolds DG. Adrenergic mechanisms in canine mesenteric circulation. Am J Physiol 1971;220:1779-85.

30. Adams RJ, Wallick ET, Asano G,
Disalvo J, Fondacaro JD, Jacobson ED. Canine mesenteric artery $\mathrm{Na}^{+}$ $\mathrm{K}^{+}$-ATPase: Vasopressor receptor for digitalis? Cardiovasc Pharmacol 1983;5:486-92.

31. Gallavan RH Jr, Tsuchiya Y, Jacobson ED. Effects of nicotine on canine intestinal bloodflow and oxygen consumption. Am J Physiol 1984;246:G195-203.

32. Fara JW, Rubinstein EH, Sonnenschein RR. Intestinal hormones in mesenteric vasodilation after duodenal agents. Am J Physiol 1972;223:1058-67

33. Granger DN, Richardson PDI, Kvietys PR, Mortillaro NA. Intestinal bloodflow. Gastroenterology 1980;78:837-63.

34. Kvietys PR, McLendon JM, Granger DN. Postprandial intestinal hyperaemia: Role of bile salts in the ileum. Am J Physiol 1981;241:469-76.

35. Lee SS, Hadengue A, Moreau R, Sayegh R, Hillon P, Lebrec D. Postprandial hemodynamic responses in patients with cirrhosis. Hepatology 1988;8:647-51

36. Kvietys PR, Granger SN. Physiology and pathophysiology of the colonic circulation. Clin Gastroenterol 1986;15:967-83.

37. Hulten L. Extrinsic nervous control of colonic motility and bloodflow. Acta Physiol Scand 1969:335:1-116.

38. Anderson PO, Bloom SR, Edwards AV, Jarhult J, Mellander S. Neural vasodilator control in the rectum of the cat and its possible mediation by vasoactive intestinal polypeptide. J Physiol 1983;344:49-67.

39. Granger NN, Kvietys PR, Barrowman JA, Perry MA, Harpter SL. Vascular physiology and pathophysiology. In: Kern F, Blum AL, eds. The Gastroenterology Annual 2. Amsterdam: Elsevier, 1985.

40. Fahrenkrg J, Haglund U, Jodal M. Nervous release of vasoactive intestinal polypeptide in the gastrointestinal tract of cats; possible physiological implications. J Physiol 1978;284:291-305

41. Anderson PO. Vascular control in the colon and rectum. Gastroenterology 1984;93:65-78

42. Campra JL, Reynolds TB. The Liver: Biology and Pathology, 2nd edn. In: Arias IM, Jakoby WB, Popper H, Schacter D, Shartitz, DS, eds. New York: Raven Press, 1988:911-30.

43. McCuskey RS. A dynamic and static study of hepatic arterioles and hepatic sphincters. Am J Anat 1966;119:455-78.

44. Legare DJ, Lautt WW. Hepatic venous resistance site in the dog: Localization and validation of 
intrahepatic pressure measurements. Can J Physiol Pharmacol 1987;65:352-9.

45. Greenway CB, Lautt WW. Distensibility of hepatic venous resistance sites and consequences on portal pressure. Am J Physiol 1988;254:H252-8.

46. Lautt WW. Afferent and efferent neural roles in liver function. Prog Neurobiol 1983:21:323-48.

47. Lautt WW. Evaluation of surgical denervation of the liver in cats. Can J Physiol Pharmacol 1981;59:1013-6.

48. Mathie RT, Lam PH, Harper AM, Blumgart LH. The hepatic arterial bloodflow response to portal vein occlusion in the dog: The effect of hepatic denervation. Pflugers Arch 1980;386:77-83.

49. Reilly FD, McCuskey RS, Cilento EV. Hepatic microvascular regulatory mechanisms. Adrenergic mechanisms. Microvasc Res 1981;21:103-16.

50. Lautt WW, Greenway CV. Conceptual review of the hepatic vascular bed. Hepatology 1987;7:952-63.

51. Lautt WW. Hepatic nerves: A review of their functions and effects. Can J Physiol Pharmacol 1980;58:105-23.

52. Koo A, Liang IY. Microvascular filling pattern in rat liver sinusoids during vagalstimulation. J Physiol
1979;295:191-9.

53. Koo A, Liang IY. Vagus-mediated vasodilator tone in the rat terminal liver microcirculation. Microvasc Res 1979;18L:413-20.

54. Greenway CV, Stark RD. Hepatic vascular bed. Physiol Rev 1971;51:23-65.

55. Reilly FD, Dimlich RVW, Cilento EV, McCuskey RS. Hepatic microvascular regulatory mechanisms. Cholinergic mechanisms. Hepatology 1982;2:230-5.

56. Gorelick FS, Jamieson JD. Structure-function relationship of the pancreas, In: Johnson LR, ed. Physiology of the Gastrointestinal Tract, 2nd edn, New York: Raven Press, 1987:1089-108.

57. Henderson JR, Daniel PM. A comparative study of the portal vessels connecting the endocrine pancreas, with a discussion of some functional implications. Q J Exp Physiol 1979;64:267-75.

58. Lifson N, Kramlinger K, Mayrand R, Lender J. Bloodflow to the rabbit pancreas with special reference to the islets of Langerhans. Gastroenterology 1980;79:466-73.

59. Baron R, Janig W. Sympathetic and afferent neurons projecting in the splenic nerve of the cat. Neurosci Lett 1988;94:109-13.

60. Greenway CV, Lawson AE, Stark RD, Vascular responses of the spleen to nerve stimulation during normal and reduced bloodflow. ] Physiol 1968;194:421-33.

61. Fillenz M. The innervation of the cat spleen. Proc R Soc Lond 1970;171:459-68.

62. Lee SS, Hadengue A, Girod C, Braillon A, Lebrec D. Divergent circulatory effects of betaxolol in conscious and anesthetized normal and portal hypertensive rats. J Hepatol 1991;12:571-5.

63. Meckler RL, Weaver LC. Characteristics of ongoing and reflex discharge of single splenic and renal sympathetic post ganglionic fibres in cats. J Physiol 1988;396:139-53.

64. Longhurst JC. Cardiovascular reflexes of gastrointestinal origin. In: Shepard AP, Granger DN, eds. Physiology of the Intestinal Circulation. New York: Raven Press, 1984:165-77.

65. Rothe CF. Control of capacitance vessels. In: Shepard AP, Granger DN, eds. Physiology of the Intestinal Circulation. New York: Raven Press, 1984;165-73-82.

66. Rowell LB, Johnson JM. Role of the sSplanchnic circulation in reflex control of the cardiovascular system. In: Shepard AP, Granger DN, eds. Physiology of the Intestinal Circulation. New York: Raven Press, 1984;165:153-63. 


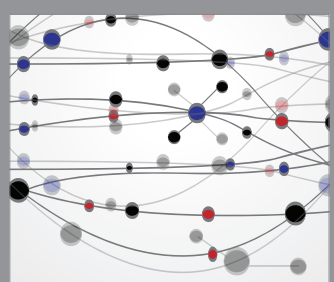

The Scientific World Journal
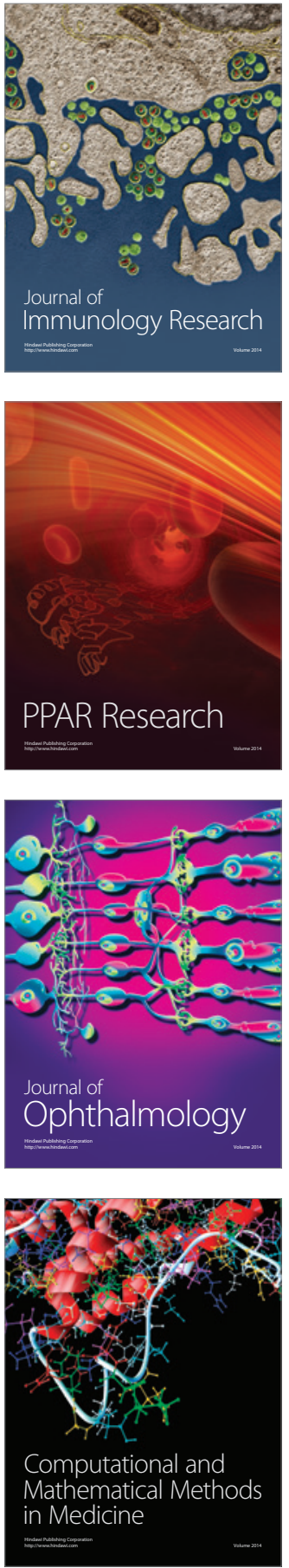

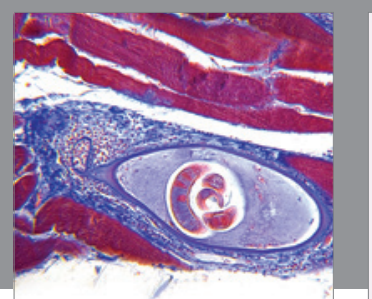

Gastroenterology Research and Practice

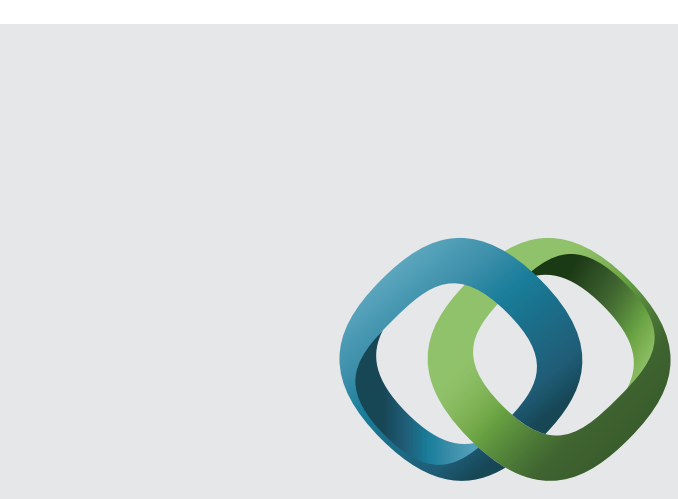

\section{Hindawi}

Submit your manuscripts at

http://www.hindawi.com
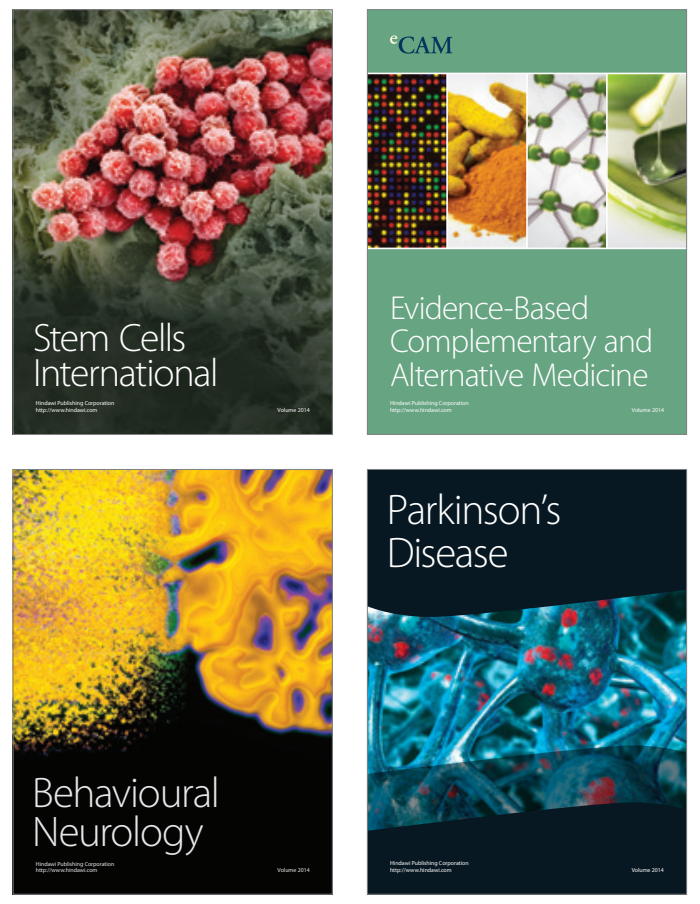
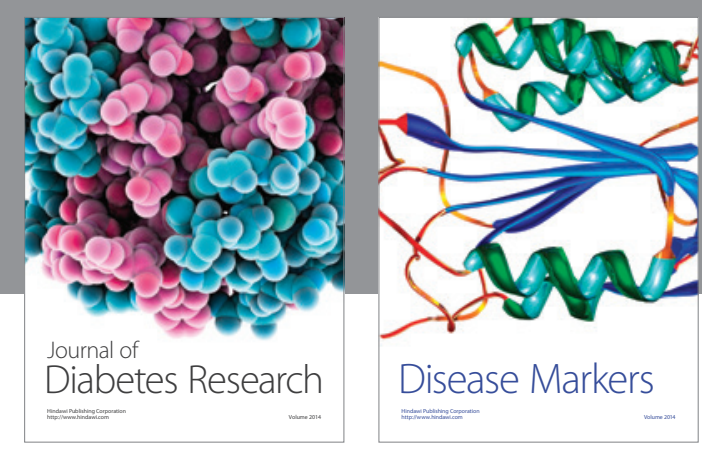

Disease Markers
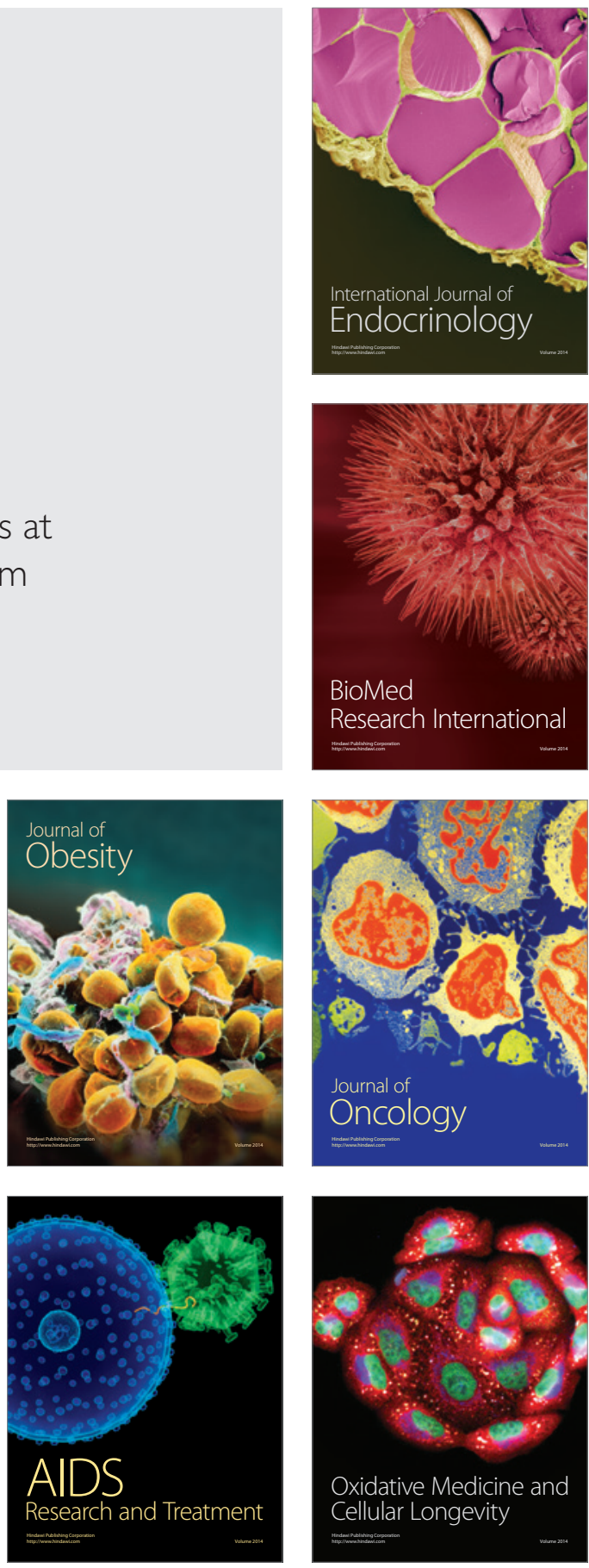